\title{
Kosen-Rufu Gleaned in the Selected Works of President Daisaku Ikeda
}

\author{
Maria Luisa A. Valdez, Ph.D \\ Batangas State University, Philippines \\ *Corresponding Author: Maria Luisa A. Valdez, Ph.D., Batangas State University, Philippines. \\ maluhvaldez888@gmail.com
}

\begin{abstract}
The future of today's world is a vision seemingly overshadowed by terror, political unrest, racial and class disparity, conflicting religious beliefs, pollution, disease, socio-economic inequality disputes, and widespread poverty. No nation is without any of the aforementioned problems and the global situation seems to worsen every minute. Thus, this study offered an analysis of kosen-rufu as a manifested core concept in President Daisaku Ikeda's selected works giving emphasis to the insights that promote ideal values that are essential to humankind's happiness. In the same light, the researcher presented the historic beginnings of kosen-rufu and its manifestations in the fields of peace, humanitarian aid, as well as educational and cultural exchange. Findings of the analysis revealed that kosen-rufu as a flourishing concept of world peace through individual happiness started off under the light of Nichiren Daishonin's Buddhist teachings and the Mystic Law of the Lotus Sutra; Kosen-rufu is immensely responsible for the sustenance of all efforts pertaining to the fields of peace, humanitarian aid and in educational and cultural exchange; and with emphasis to Ikeda's message that essentially heralds the individual's capacity to pursue the inner revolution necessary for a greater revolution of humanity, one can never disregard the importance of considering kosen-rufu as an integral and formidable step toward peace, harmony and the happiness of everyone.
\end{abstract}

Keywords: Daisaku Ikeda, Educational and Cultural Exchange, Happiness Humanitarian Aid, Kosen-rufu, Soka Gakkai International, and World Peace

\section{INTRODUCTION}

A myriad of problems stares at humanity in today's time. Seemingly threatening the very existence of man are the endless conflicts and wars that take countless lives and displace innocent souls by the thousands. The onset of modern technology paved the way for the development of the most sophisticated weaponry ever known to man. Even more alarming is the irony that in pursuit of order, chaos brought about by the aftermath of all the armed conflicts inevitably causes millions of helpless souls to suffer. The future of today's world is a vision seemingly overshadowed by terror, political unrest, racial and class disparity, conflicting religious beliefs, pollution, disease, socio-economic inequality disputes, and widespread poverty. No nation is without any of the aforementioned problems and the global situation seems to worsen every minute.

The civil unrest brought about by the most recent terror attacks that rattled the United States and some countries in the West provide a valid proof of the current situation of the contemporary world; Russia and other countries in Europe are locked in a political dispute concerning Ukraine that resulted in sanctions and trade embargo that inevitably affected millions of people residing in Europe; the violence upheld by the Islamic State of Greater Levant currently places the Middle East and the Northern Africa in great turmoil; the advances of China amidst territorial disputes in the South China Sea threaten peace in the whole of South East Asia; North Korea's nuclear drives continue to be a flash point that endangers peace on the peninsula, and the recent war caused by the Islamic State of Iraq and al-Sham (ISIS)-affiliated militant movement in Marawi, Philippines that created conditions for instability in the region. These are but a few examples of events that currently threaten the future of humanity, all of which bring about the great question of how humanity can save the situation.

Since its inception, the United Nations (UN) has long since been a proponent of global unity by serving as facilitators of international cooperation in matters concerning international laws, global economic development, international security, and the overall progress of society, to name a few of its 
primary missions as an international organization. The United Nations have always been on call in matters concerning the settlement of disputes to prevent wars by way of suggesting peaceful options in the peace process, as well as being on point to give aid during the times when wars become inevitable. The UN Security Council, upon the directive of the UN Security General and with the support of the UN General Assembly has long played the part of primary peacekeeper all throughout the world. For decades, the United Nations have been key players in the prevention of conflicts in the pursuit of world peace (Agrawal, 2011) ${ }^{[1]}$.

In similar fashion, Soka Gakkai International (SGI) are in their own way proponents of the pursuit of universal happiness, prosperity and world peace. SGI is a Buddhist organization whose key contributions to society include fostering an overall environment of spiritual awakening and universal cooperation as part of their mission to educate people in the practice of compassion in their personal and daily lives. Being Buddhists, it is their utmost goal to pursue the universal condition of inner peace toward the realization of prosperity and world peace by way of empowering people to the realization of their own unique potentials. It is the belief of SGI that the fulfillment of world peace and the prosperity of society rely on every individual's personal ability to practice compassion by being able to postpone their achievement of Nirvana in service to other people who are suffering. In SGI President Daisaku Ikeda's 2016 Peace Proposal, he mirrored this ideal by citing American political philosopher Martha Nussbaum's warning about the pitfalls of short-term interests, in reference to man's tendency to accept the suffering of others which may erode the very foundation of human survival ${ }^{[2]}$. In the said peace proposal, Ikeda voiced out the need for global interdependency and expressed the SGI's stand in humanitarian issues in the UN's first World Humanitarian Summit held in Istanbul, Turkey last May 2016, as it has long since been the SGI's thrust to work with the United Nations in such issues ${ }^{[2]}$. As a Buddhist lay organization, SGI has remained consistent in voicing out the need for human revolution through universally-oriented bodhisattva practice ${ }^{[3]}$.

The SGI's dedication to the global thrust of promoting education, culture and peace is firmly rooted on the ideals of Buddhism, according to the philosophy of Nichiren Daishonin. The Mahayana traditionbased Japanese Buddhist movement of Nichiren Buddhism gives emphasis on every individual's role in self-improvement as the key step toward contributing to a better world ${ }^{[4]}$. It is part of the SGI's adherence to Nichiren Buddhism to facilitate life transformations which they believe will radiate outwardly toward society and the rest of the world.

As part of their efforts concerning peace in the community, the SGI has been very active in facilitating educational and cultural events in support of various political and economic proposals which include eradication of weapons of mass destruction and the promotion of economic equanimity [3].

To understand better the concept of kosen-rufu, it is important to trace the beginnings of SGI President Daisaku Ikeda. The Tokyo-born Japanese proponent of peace is a Buddhist philosopher, educator, poet and author who grew up in the backdrop of humble beginnings, being the fifth child to a family of seaweed farmers who raised eight children in the midst of the aftermath of World War II. The first-hand experience of the horrors of war provided Daisaku Ikeda the necessary motivation to working towards a lifelong goal of peace. He became Soka Gakkai's third president and eventually founded Soka Gakkai International, which, under his leadership, gave birth to an era of transformation fueled by his lifetime of dedication to initiatives that serve worldwide endeavors of education, culture and peace.

Daisaku Ikeda firmly believes in the importance of communication through dialogues and forums as cornerstones of peace, and since the 1970's, he has been very active in discourses worldwide in the areas of politics, education and culture. Ikeda has fathered numerous independent and non-profit organizations aimed at promoting the development of interdisciplinary and cross-cultural cooperation on various global issues.

With the Buddhist tenet of the sanctity of human life adopted by Ikeda as his core ideal, he views world peace as being dependent on an individual's personal transformation as a vital step in the attainment of lasting peace and ultimately, the overall happiness of the society and the whole humanity. Rather than being solely dependent on societal reform, Ikeda gives emphasis on the empowerment of the individual, and this thought was conveyed by Ikeda in his most-renowned work The Human Revolution where he outlined Soka Gakkai's principle that gives importance to an 
individual's role in the achievement of a nation's destiny and ultimately, in the destiny of mankind, by way of an inner revolution (Kawada, 2016) ${ }^{[5]}$.

Thus, the SGI followers consider kosen-rufu as a very important core ideal. Often mentioned in the same light as world peace, kosen-rufu is better understood as the endeavoring of global harmony and peace through individual happiness. It refers to the vision of peace as a product of a universally accepted value anchored on the unwavering respect for the dignity of human lives. In a nutshell, SGI considers kosen-rufu as the relentless and endless endeavor to elevate human dignity, and this they pursue by way of being active in the area of humanitarian aid, cultural and educational exchange and peace, as integral aspects of kosen-rufu that are vital to the pursuit of the happiness of mankind.

As can be recognized in the contemporary world, the alarming fact that the utter inability of people to show compassion for the dignity of others is a thriving human trait. Certain ideologies point out the expendability of lives and this erodes the core of human dignity. The resignation and acceptance of one's failure in the pursuit of personal excellence more often than not translates to the denial of opportunities for others. As a result, the rippling effect of the lack of confidence in the self and in others gives birth to the option of violence ${ }^{[6]}$.

Hence, now can it be considered as the perfect moment for people to reawaken the resolve to start anew. Every person's individual lives deserve a paradigm shift en route to a reconstruction of a personal revolution that will bring about a contagious effect on society through every individual's life transformations.

This study will prove integral to a number of individuals, namely to members and managers of academe alike in considering Ikeda's fundamental principle of kosen-rufu as a prime example of teaching from which an abundance of values may be gleaned; to professionals in various fields of practice in educating themselves with Ikeda's use of kosen-rufu in his messages as a better example of the usage of language in a thought-provoking context, in a way that is applicable to their fields of expertise, while enhancing the value of human dignity and promoting the overall sense of an individual's limitless potential in the workplace; to students of literature who may understand the concept of kosen-rufu as an integral vantage point in the appreciation of literature with regard to Ikeda's usage of ideals in his works, and convince them to pursue literary analysis as an essential academic exercise; to instructors and professors of literature in the colleges and universities who may learn from the application of Ikeda's concepts as well as the researcher's approach in the literary analysis; to the researcher who conducted this study as her humble contribution to the ever-growing works that highlight Japanese Buddhism; to future researchers as this study can be used as reference in future research on the same subject; and to the ever-enduring writers and fans of literature who may be able to appreciate kosen-rufu as an example of a spiritual concept aimed at society's improvement.

With all these thoughts being considered, the researcher, who is currently a lecturer in literature at the Batangas State University, Philippines felt the deep motivation and the drive to pursue an analysis on kosen-rufu and the insights gleaned in the works of Daisaku Ikeda that foster and promote the values integral to happiness.

\section{OBJECTIVES OF THE STUDY}

The study offered an analysis of kosen-rufu as a manifested core concept in Daisaku Ikeda's selected works giving emphasis to the insights that promote ideal values that are essential to happiness. In the same light, the researcher presented the historic beginnings of kosen-rufu and its manifestations in the fields of peace, humanitarian aid, educational and cultural exchange.

\section{Method AND MATERials}

\subsection{Research Design}

This paper utilized the method of qualitative analysis in studying kosen-rufu as manifested in Daisaku Ikeda's works, with consideration to the insights that promote integral values that are important to human happiness. Qualitative research, according to Suter (2012) ${ }^{[7]}$, must adhere to the philosophy that the realities experienced by readers in understanding the complexity of a phenomenon must be taken in consideration.

The reader's various realities can be manifested in a variety of ways which include the genres of literature that are known as essays and speeches or discourses. As such, philosophical approach, as 
well as historical approach was used as bases for the analyses in this study. Human experiences are defined by social, cultural and political influences, hence, human experiences are intertwined with the said concepts, according to Ary, et al. (2006) ${ }^{[8]}$. Therefore, the principles in the context of a Buddhist builder of peace were considered in the analysis of the identified works of literature, as these provide substantial and significant insights on the author's motivations with regard to his core principle.

Patton (2002) ${ }^{[9]}$ stated that qualitative data analysis aims to point out the emergence of themes, concepts, patterns and insights, hence, this research likewise utilized textual analysis, a systematic technique in message handling and context analysis (McMillan, 2000) ${ }^{[10]}$. Data analysis in this study was therefore focused on seeking patterns and extracting insights from Daisaku Ikeda's selected literary narratives and/or image data.

\subsection{Treatment of Materials}

Integral features in the treatment of this paper's materials were considered by the researcher in conducting this study.

As with other art forms, literature is set on specific standards from which the particular selections can be subjected for analysis. In this research, the guidelines cited by Stott (2014) ${ }^{[11]}$ afforded the researcher the necessary bases for selecting the works of Daisaku Ikeda with regard to their universal appeal, permanence, artistry and style, intellectual value, spiritual value, and suggestiveness.

The selected works of Daisaku Ikeda were considered universally appealing due to its relevance in nature. The selections were likewise considered for their permanence, as they exude an appeal that is enduring and lasting. With reference to artistry and style, the selections appeal to the overall sense of appreciation and beauty that is unique to Daisaku Ikeda and allow readers to be immersed in the writer's perspective. As regards their intellectual value, the selections were mentally-stimulating and thought-provoking and help the readers gain an insight in their lives and realize the valid truths about kosen-rufu, humanity and life in general. The selection's spiritual value was likewise prominent in the sense that their underlying thoughts on morality have the potential to bring out the better person within the readers. In reference to suggestiveness, the selections manifest the power of literature to appeal to the power of emotion. The readers are presented with thoughts from which insights can be evoked beyond their everyday life experiences.

For the purposes that may well serve this study, the following masterpieces of Ikeda were subjected to analysis due to their philosophical credibility: 2015 Peace Proposal, A Shared Pledge for a More Humane Future: To Eliminate Misery from the Earth, 2016 Peace Proposal, Universal Respect for Human Dignity: The Great Path to Peace, and Awakening to Our Mission, 2003.

From these literary pieces, readers will be able to absorb the thoughts as presented by Ikeda and obtain an insight on the seeds of his most important teachings that are likewise being shared by Ikeda for humanity's awakening. The prose of Daisaku Ikeda, being the primary and core source of this research, was chosen in congruence to the criteria that were cited for purposes of this study. The thought and veracity of Daisaku Ikeda's statements in the selections were systematically chartered and analyzed by way of subjecting them to internal and external critique. In this light, the researcher exercised freedom in defending her understanding and evaluation of the selections, with reference to the insights evoked by kosen-rufu, as well as by defining the coherence of language to the theme, its relevance to the situation, and the suitability of language to the literary selections under study.

Notes were carefully taken by the researcher to assure the maintenance of congruence between the theories that explained the concept kosen-rufu. As such, the coding units included by the researcher were the following categories: the historical beginnings of kosen-rufu in the Buddhist tradition, the manifestations of its practice in the fields of peace, humanitarian aid, educational and cultural exchange, and the insights gleaned in the selections that promote the values integral to humankind's happiness.

\section{RESULTS AND DISCUSSION}

\subsection{The Historical Beginnings of Kosen-Rufu in the Japanese Buddhist Tradition}

The historical beginnings of kosen-rufu in Japanese Buddhism can be traced to Japanese Buddhist Nichiren, who, during his lifetime spanning 60 years until his death in 1282, set himself apart from his 
Buddhist counterparts by making mention and incorporating the phrase in his teachings. While the concept of kosen-rufu may not be easily defined due to the breadth of its definition, it is in itself encompassing and not too complicated to fully comprehend. In order to understand the concept of kosen-rufu, it is noteworthy to consider Daisaku Ikeda's works as primary focal point while maintaining Nichiren's teachings in the periphery, being the foundation of kosen-rufu itself, and the relationship between the two as the framework that established SGI as key pillars of Japanese Buddhism. It is also important to grasp the idea within the concept of kosen-rufu that in its encompassing nature lies within its definition.

Kosen-rufu is an ancient Japanese phrase that first appeared in Chapter 23 of the Lotus Sutra. Written in Chinese characters, the phrase literally translates to "widely", or "widespread", "declare" or "declaration", "flow", and, "promulgate" or "promulgation". In the 23rd Chapter of the Lotus Sutra where Buddha likewise metaphorically suggested its sovereignty over other sutras, he declared that 500 years after his physical death, kosen-rufu should have been accomplished worldwide, and that his followers, in reference to the contemporary Buddhist practitioners, must strive for its flow to be unending, or in other words, for kosen-rufu to thrive in society. Kosen-rufu in Buddha's own words therein was implied in its global application in the aforementioned context.

As previously mentioned, Japanese Buddhist Nichiren distinguished himself apart from his Buddhist counterparts by integrating kosen-rufu in his approach to teaching Buddhism. To him, the attainment of happiness and enlightenment is dependent upon the level of happiness and the state of enlightenment of others. The concept of enlightenment as a personal and inward virtue was an idea that Nichiren shunned along with his firm stand against the cultivation of Buddhism in order to attain a better life after death. To him, the idea of enlightenment as a private and inward goal prevents it from radiating outwardly, and the reward-based approach to practicing Buddhism would reflect man's acceptance of his failure to overcome suffering. Nichiren believe that by adhering to the two previously mentioned ideas, Buddhist practitioners give up the opportunity to transform society; hence his rejection of the said ideas, in contrast to other Buddhists of his time who believed that humanity will undergo a series of evolving stages, which includes a time when Buddhism will cease to be practiced. Nichiren was known to be steadfast in his teaching that adhered to the core Buddhist principle that contrary to what other Buddhists at the time believed, happiness and enlightenment is achievable by anyone and everyone.

Nichiren propagated his view on enlightenment not as an end, but instead as a means to an end. However, Nichiren never implied a state wherein Kosen-rufu will ever cease; for him, it forms the core of enlightenment, as fundamental basis for all humanistic actions. Daisaku Ikeda and the rest of the SGI followers adhere to this basic teaching of Nichiren: that the condition of being enlightened represents a state of boundless vigor, limitless wisdom and unending compassion, all of which were coherently and actively propagated by Soka Gakkai's second president Josei Toda, who applied the rhetoric of "human revolution" to drive his point across in defining enlightenment as a transformational process by which man frees himself from being bound by his "lesser self".

It is likewise important to note that Soka Gakkai International mirrored the very same understanding that Nichiren reflected during his time, when it was known to Buddhists as the period of the "Latter Day of the Law". Said to begin between 2000-2500 years after Gautama Buddha's death, the said time period was predicted to be one of degeneration, wherein Buddhism would have lost its grasp on the people, and the secular control of ruling regimes and empires would have faltered. Historical events that happened a year prior to Nichiren's birth seemed to confirm the prophecy of the Latter Day of the Law, when a Buddhist-supported emperor attempted to rise to power by an uprising that failed to unseat the then-Samurai run government. This failed insurgency attempt amidst the support of Buddhists reflected a sign of times that hinted at the fulfillment of the said prophecy. The aftermath of this unfortunate event, together with the plagues, disasters, famine and other natural events shaped the mind of Nichiren. However, instead of accepting the stage of the "Latter Day of the Law" as a period in time to surrender to suffering, Nichiren understood the sign of the times to be the age wherein Buddhism would ultimately need a revival, and interpreted the sutras as to having predicted a period of time wherein personal happiness will cease to be an option. Thus, Nichiren embodied the fundamental belief of overcoming the root of suffering, as opposed to surrendering to it. 
This core ideal of kosen-rufu reverberates the message of the Lotus Sutra that teaches humanity to believe in the Buddha within them, and this core belief stands as the foundation of the ideals of Daisaku Ikeda and the rest of the SGI followers, who define kosen-rufu as the endless endeavor to elevate the dignity of mankind. To them, the practice encompasses the relentless aspiration to enlighten humanity towards understanding their ultimate potential. Kosen-rufu is simply what is universally known as world peace, and in a broader sense, it speaks of the vision of a peaceful society amidst the global acceptance of respect for human life as a core value ${ }^{[12]}$.

According to Ikeda, kosen-rufu refers to the process of spreading the Mystic Law from one person to another and likewise from a group to an even larger multitude. However, he dispels it as being a matter of integral numbers which have an end point; rather, he refers to it as an endless process or an eternal flow of the Mystic Law. He stated that there will never be a moment in time when people will accept the end of kosen-rufu, as it would inevitably result to the ultimate failure of human revolution, the proverbial spiritual death of humankind. To Ikeda, kosen-rufu is endless in the sense that people may ascribe interpretation to it in terms of certain conditions which may be realized, but the formlessness of kosen-rufu renders to it to be limitless.

In reference to the etymology of the phrase, kosen translates to "widely declare", and in this context "widely" refers to a multitude of people and "declare" signifies a valid statement proclaiming one's principles, philosophy and ideology. "Ru," in this sense, refers to the flow of a river's torrent, and "fu" which translates to cloth, signifies the interwoven and interlinked pattern that is inherent in the phrases' nature. To briefly explain the underlying concept within kosen-rufu as regards its etymological meaning, Ikeda maintains that the teaching of Mystic Law is boundless, formless and limitless. It is ever encompassing and does not distinguish among classes. He likens kosen-rufu to the interwoven thread that forms a cloth, with the vertical threads standing for the transfer of Nichiren's teachings throughout the ages, from an older and wiser generation to a younger and more vital generation who will benefit from Nichiren's wisdom. Daisaku Ikeda likewise alludes to the horizontal threads of a cloth as the passing of Nichiren's teachings across social classes and territorial boundaries. Kosen-rufu, therefore, is the timeless endeavor to propagate the philosophy and teachings of Nichiren Daishonin as a proper way to happiness and a key principle in the pursuit of global peace and harmony. This is due to the fact that man is deemed incapable of surviving all by himself. True to its Japanese transcription, the word "human being" is written with two Chinese characters that literary translate to "between people". This interdependence of human beings likewise suggested in the etymological sense should be insightfully understood by people to promote a better understanding and acceptance of the philosophy that is rightfully theirs, as it is within the hallmark of Buddhist philosophy for man to have the innate desire to share the truth.

In essence, kosen-rufu likewise refers to the interpersonal sharing of thoughts by way of honest and heartfelt communication in the overall ambiance of harmony, togetherness and friendship on the path toward becoming happier and better versions of their old self. This picture of a tightly-knit conglomeration of individuals collectively on a journey for the happiness of mankind is what constitutes kosen-rufu ${ }^{[13]}$.

\subsection{The Practice of Kosen-Rufu Manifested in the Fields of Peace, Humanitarian Aid, Educational and Cultural Exchange}

\subsubsection{In the Field of Peace}

SGI is a Japanese Buddhist lay organization that is considered a key figure in the field of peace, having been able to work with the United Nations as consultants within the UN's list of Faith Based Organizations ${ }^{[2]}$. SGI's successful participation in the field of peace can be attributed to the guidance of Daisaku Ikeda, who swears by his vision of a united effort that is not bound by the limitations of self-sacrifice which to him suppresses or kills a person's sense of individual worth. To him, true unity is attained by every individual in being able to successfully break out of the ego's confinement. The concept of "many in body, one in mind" is given life by Ikeda in his guidance to the members of SGI and constantly appeals to each and every follower to pursue the development of their own unique potentials. This principle is what constitutes the SGI's successful and united endeavors in the field of peace ${ }^{[14]}$. It is important to note that kosen-rufu is exemplified by Daisaku Ikeda by way of constantly reminding the SGI followers to be relentless and untiring in fostering peace through friendly and personal exchange aimed at transitioning from ideologies based on the philosophy of war which 
confine mankind to a restricted space, towards a non-exclusive culture of global harmony and peace wherein the diversity of humanity is dignified and celebrated with a united vow to protect peace and human life ${ }^{[15]}$.

\subsubsection{In the Field of Humanitarian Aid}

Since the SGI was formed under the guidance and leadership of Ikeda, the organization has been relentlessly active in matters spearheaded by the United Nations in the field of humanitarian aid. The practice of kosen-rufu is ever evident in Ikeda's essays and discourses addressing humanitarian issues as part of SGI's thrust in being a key Faith Based Organization that is welcomed by UN in the consultatory aspect of the international organization's role in the peace process. Daisaku Ikeda maintained kosen-rufu as his core principle when he delivered his 2015 Peace Proposal that envisioned a future that would be defined and determined by the intensity and depth of the people's commitment, and gave weight to the necessary steps to be undertaken by everyone, including the younger and future generations to endure and overcome the sufferings that persist in humanity ${ }^{[15]}$. $\mathrm{He}$ likewise referred to the theme of "re-humanization of politics and economics" as essential means for humanity to alleviate suffering ${ }^{[15]}$, and cites solidarity of the common people in voicing out their commitment to a brighter future, as the "most important driving force" for the aforementioned theme [15].

He likewise embodied kosen-rufu in reference to the success of solidarity not being anchored on sheer numbers; rather, he gave emphasis to the importance of the depth and strength of people's united efforts en route to the re-humanization of politics and economics. Ikeda believed that domestic and international solidarity is defined by individuals who are driven by the intention to see the pivotal moment of history when no human soul will suffer alone in misery ${ }^{[15]}$. In the same light, Ikeda remained true to the core thought of kosen-rufu when he, once again made mention of the organization's consistent thrust in the field of humanitarian aid, as he declared the SGI's participation in the upcoming World Humanitarian Summit, the first ever international humanitarian dialogue with the United Nations as proponents ${ }^{[2]}$.

\subsubsection{In the Field of Educational and Cultural Exchange}

Ikeda himself is an adherent to the belief that for friendship to ceaselessly evolve, it requires one to shun being self-oriented and instead allow one's self to be illuminated in the brilliance of others. He described his dialogue with Dr. Arnold Toynbee, a renowned British historian, over four decades ago as a groundbreaking event which inspired him to pursue exchanges with key figures from diverse cultures, religious and academic backgrounds. He ascribes the success of his personal and the whole of SGI's cultural and educational exchanges to the overall shared concern for humanity, and this, in essence, can be gleaned as an exemplification of kosen-rufu ${ }^{[15]}$.

Under the leadership of Daisaku Ikeda, SGI have been stewards in the field of cultural and educational exchange, as it is within Daisaku Ikeda's directives to create opportunities for people of all countries and regions. Within the mantra of kosen-rufu, Ikeda pivoted the SGI to pursuing initiatives that promote the extension of friendship and building of trust worldwide. He echoes the SGI's hopes that hinge on the bonds of friendship as a countermeasure to ideologies that are anchored on xenophobia, and envisions a world built upon the solid foundations of societies that will remain unaffected by negativity. Ikeda cited SGI's modest efforts in the light of kosen-rufu as he heralded the organization's timeless efforts to preserve the lines of communication via cultural and educational exchanges which have been spearheaded by him and the whole of SGI over the course of its inception [15].

\subsection{The Insights Gleaned in the Selections that Promote the Values Integral to Happiness}

As gleaned in the selections of the works of SGI President Daisaku Ikeda, kosen-rufu refers to the timeless, formless and limitless pursuit of enhancing the value of human dignity, and this core thought includes the promotion of an awakening of humanity to an overall sense of boundless worth and potential.

While ideologically, it may seem impossible to attain a state wherein all people will be awakened to their limitless worth and boundless potential, it is best to understand kosen-rufu in this context, as being relentless, timeless, and unending, and more a means than an end, is what kosen-rufu is all 
about. The selections of Daisaku Ikeda all contained the message of kosen-rufu, as exemplified by the SGI leader.

Ikeda's essays and works are full of insights that promote the values integral to happiness: he believes in the power of the individual to influence others, he believes that kosen-rufu, as with charity, essentially must begin at home, or in this case, from within the individual. He outlined the radiating effect of kosen-rufu in a practical manner when he spoke of the concept as the very example every individual must set in their lives. In this sense, kosen-rufu can be insightfully understood as including and not being limited to the manner by which people illuminate themselves and everyone else around them. It encompasses the way of treatment with respect to every individual's capability to attain the state of Buddhahood, which can be seen in the way a person effortlessly radiates a feeling of warmth toward others. It includes the respect for human life as reflected by the way people interact with one another, wherever they are, be it within their families, workplaces, schools, and communities. It is in the sweet nothings a man tirelessly whispers to his wife, it is the words of assurance of a mother to her child, as is also in the small but pleasant talks a person shares with his neighbor. In essence, kosenrufu is the shared pursuit to foster a higher level of human dignity across communities, societies and nations.

Kosen-rufu is aimed at oneself but is not bound within the limits of one's ego, but instead is the positivity aimed at the lives of people everyone is bound to come in contact with. Ikeda transmitted his messages with the intention that people may realize the unique virtue within themselves, that they may be able to endure, to thrive and ride life's flow unaffected and uncompromised by any form of obstacle life throws in front of their paths. He, however, does not intend to dismiss one's grief over the loss of a loved one, but instead wishes to persuade one to summon all the positive energy which will be integral to the healing process, and this, he believes, is hinged upon faith.

It can be learned from Ikeda's works that he does not have a utopian ideology of envisioning a perfect society; rather, he believes that the endless endeavor that is kosen-rufu, together with the guidance of the Lotus Sutra and Nichiren's teachings, is the rightful path to happiness. Ikeda believes in the boundless energy of man from within, and calls on everyone in a united mission to spread the Mystic Law worldwide. Ikeda values the importance of a heartfelt communication with others, and to him, while it may not be possible to sway others to embracing a particular faith, what is important is the gesture by which knowledge and the message of peace and happiness is transmitted from one person to another. This manner of interaction, to Ikeda, is a simple way to communicate with the Buddha from within, and is already in itself a successful implantation of the seed of compassion and joy, ready to be nurtured and nourished, and while it may not be instantly realized, Ikeda considers being able to communicate to others about Buddhism as his great privilege and a gift that he is very much willing to share to everyone.

With the literary pieces of Ikeda, one can summarize kosen-rufu as the fuel behind his envisioned human revolution, with every individual effort considered by him as being the foundation of this formless, boundless, selfless and limitless endeavor to elevate the dignity of human life in the pursuit of happiness.

\section{CONCLUSIONS AND RECOMMENDATIONS}

From the selections of Daisaku Ikeda, the following findings are presented by the researcher: Kosenrufu as a flourishing concept of world peace through individual happiness started off under the light of Nichiren Daishonin's Buddhist teachings and the Mystic Law of the Lotus Sutra. It is the driving force behind the Daisaku Ikeda-led Soka Gakkai International, and it in itself is a valid manifestation of the level of respect for the human life's dignity exemplified by the organization's great leader. Kosen-rufu is immensely responsible for the sustenance of all efforts pertaining to the fields of peace, humanitarian aid and in educational and cultural exchange. The tireless efforts of the SGI under the leadership of Ikeda in the previously mentioned fields exemplify kosen-rufu in every aspect. Of equal importance is the amount of insights gleaned by the researcher in the course of analyzing the selected works of Daisaku Ikeda. With emphasis to Ikeda's message that essentially heralds the individual's capacity to pursue the inner revolution necessary for a greater revolution of humanity, one can never disregard the importance of considering kosen-rufu as an integral and formidable step toward peace, harmony and the happiness of everyone. 
In this light, the researcher offers these recommendations: that this study be considered by members and managers in the academic field as a worthy example of the necessary methods of approaches which may be applied in their respective academes with regard to the researcher's methodology in analysis, evaluation and gleaning of insights from Ikeda's core thought of kosen-rufu; that this study may inspire students of literature to a greater appreciation of the distinct style of persuasion utilized by Daisaku Ikeda as an example of the inherent ability of Buddhist-inspired literature to evolve the most positive of thoughts; that this paper may be considered by working professionals as a focal point in the development of different persuasive and thought-provoking concepts which may improve interpersonal harmony in the workplace and further induce productivity in their respective fields; that university and college instructors and professors of literature may consider this study as a worthy pedagogical example which may bring about a more-positive and a happiness-oriented ambiance to entice students into a new-found appreciation of literature; that this paper may inspire fans of literature, writers and future researchers to the worthy endeavor that is kosen-rufu, which may inspire them to pursue future analyses of the said concept, with this paper as point of reference.

\section{ACKNOWLEDGMENT}

The researcher wishes to express her personal thanks and appreciation to those who helped make this humble work a reality. First and foremost, she wishes to thank God, for inspiring her during the writing process. To Dr. Tirso A. Ronquillo, the Batangas State University President and the other University officials most especially to Dr. Erma B. Quinay, the Vice President for Academic Affairs and Prof. Enrico M. Dalangin, the BatStateU ARASOF Nasugbu Executive Director, for the motivation that helps hasten the completion of this study. To Mr. Thaakor Pathak, for his wisdom that drew up essential and relevant dimensions in this research. To the pool of writers whose works were included in this study for posterity, for their emboldened wisdom in every page of this research. To all of you, the researcher owes her deep gratitude.

\section{REFERENCES}

[1] Agrawal, Abhishek (2011) Role of UN in Maintenance of International Peace \& Security (October 23, 2011). Available at SSRN: http://ssrn.com/abstract=1948054 or http://dx.doi.org/10.2139/ssrn.1948054

[2] Ikeda, Daisaku (2016) Peace Proposal, Universal Respect for Human Dignity: The Great Path to Peace (p.5); url: www.daisakuikeda.org/main/peacebuild/peace-proposals/pp2016.html; date retrieved 03/30/ 2016.

[3] Kawada, Yoichi (2016) From Inner Peace to World Peace: A Buddhist Perspective; Published in World Order for a New Millennium, St. Martin's Press, 1999; url: http://www.sgi.org/resources/studymaterials/from-inner-peace-to-world-peace-a-buddhist-perspective.html/; date retrieved: 03/20/2016.

[4] Bbc.co.uk Website (2016) Nichiren Buddhism; url: http://www.bbc.co.uk/religion/religions/buddhism/ subdivisions/nichiren_1.shtml/; date retrieved: 03/30/2016.

[5] Kawada, Yoichi (2016) Daisaku Ikeda; url: http://www.sgi.org/about-us/founding-presidents/daisakuikeda.html/; date retrieved: 03/20/2016.

[6] Sgi.org Website (2015) Kosen-rufu; url: http://www.sgi.org/about-us/buddhism-in-daily-life/kosen-rufu. html; date retrieved: 03/28/2016.

[7] Suter, W. Newton (2012). Introduction to Educational Research. University of Arkansas at Little Rock Sage Publications, Inc.

[8] Ary, Donald, Lucy Cheser Jacobs, Asghar Razavieh, Christine K. Sorensen (2006). Introduction to Research in Education. Wadworth: Belmont, California, USA.

[9] Patton, M. Q. (2002). Qualitative Research and Evaluation Methods.Thousand Oaks, California, USA: Sage.

[10] McMillan, S. J. (2000). The Microscope and the Moving Target: The Challenge of Applying Content Analysis to the World Wide Web. Journalism and Mass Communication Quarterly, 77(1), 80-98.

[11] Stott, Monica (2014) What are the Literary Standards in Literature?; url: http://arts-literature. blurtit.com/1120166/what-are-the-literary-standards-in-literature; date retrieved: 12/31/2014.

[12] Soka Gakkai International Buddhism in Action for Peace Website (2015) Kosen-rufu: Philosophy: From Fighting for Peace by Daisaku Ikeda; url: http://www.sgi.org/about-us/buddhism-in-daily-life/kosenrufu.html; date retrieved: 03/13/2016.

[13] Soka Gakkai International Buddhism in Action for Peace Website (2015) Understanding Kosen-rufu: Excerpted from Discussions on Youth (SGI-USA, 1998); url: http://www.sgi.org/about-us/presidentikedas-writings/kosen-rufu.html; date retrieved: 03/13/2016. 
[14] Ikeda, Daisaku (2003) Awakening to Our Mission, World Tribune (p.2); url: www.sgi-usa.org; date retrieved 03/28/2016.

[15] Ikeda, Daisaku (2015) Peace Proposal, A Shared Pledge for a More Humane Future: To Eliminate Misery from the Earth (p.8); url: www.soka-ebook-store.com/consumer/items/1291; date retrieved 03/28/2016.

\section{AUTHOR's BIOGRAPHY}

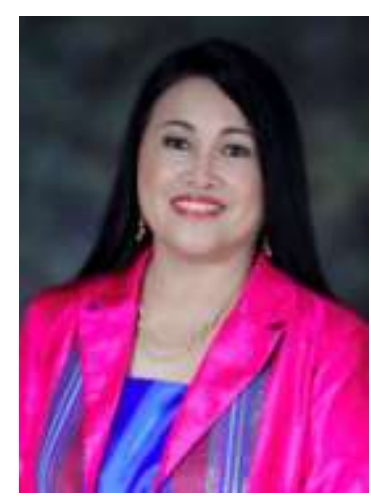

Maria Luisa A. Valdez, earned a Doctor of Philosophy degree with a specialization in English from the Batangas State University (BatStateU), Philippines. She has published several researches in reputable international refereed journals and presented papers on local, national and international research fora. Likewise, she is an editorial board member and a peer reviewer of various international refereed journals. Her research interest centers on education, humanities and social sciences specifically on contemporary social issues like peace education, gender equality, and environmental issues manifested in the selected contemporary literary works in English. She is currently a professor in BatStateU and a visiting professor of the Thai Nguyen University (TNU) International Training and Development Center (ITDC), Socialist Republic of Vietnam.

Citation: Maria Luisa A., Valdez, Ph.D. "Kosen-Rufu Gleaned In the Selected Works of President Daisaku Ikeda." International Journal on Studies in English Language and Literature (IJSELL), vol 5, no. 11, 2017, pp. 28-37. doi:http://dx.doi.org/10.20431/2347-3134.0511004.

Copyright: (c) 2017 Authors. This is an open-access article distributed under the terms of the Creative Commons Attribution License, which permits unrestricted use, distribution, and reproduction in any medium, provided the original author and source are credited. 